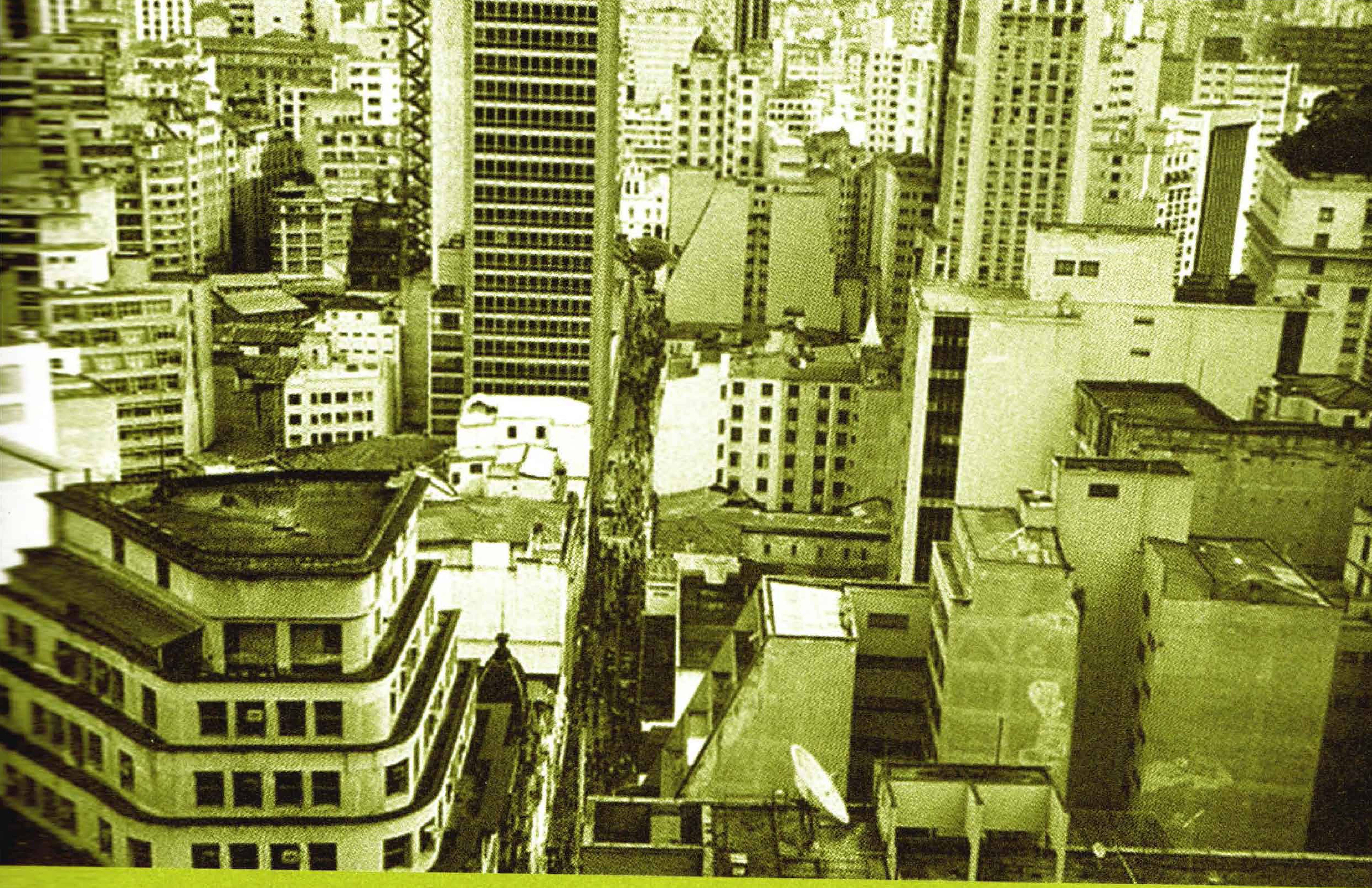




\section{Moacir Gadotti}

Doctor en Ciencias de la Educación de la Universidad de Ginebra, profesor titular de la Universidad de Sao Paulo, director del Instituto Paulo Freire y autor, entre otras obras, de Historia de las ideas pedagógicas (Atica, 1993), Pedagogía de la praxis (Cortez, 1994), Paulo Freire: una biobibliografía (Cortez, 1996), Perspectivas actuales de la educación (Artes Médicas, 2000), Pedagogía de la Tierra (Peirópolis, 2001) y Los maestros de Rousseau (Cortez, 2004). La mayoría de estas obras están traducidas al español.

\section{Resumen}

Este trabajo toma como referencia conceptos de Ciudad Educadora planteados por Freire, la Carta de principios básicos de la ciudad que educa, así como distintos manifiestos que han tenido lugar desde su promulgación desde principios de la década del noventa. Relaciona conceptos de Ciudad Educadora provenientes de la Declaración de los Derechos del Hombre y del Ciudadano de 1789, con los de Freire, Cortina, Genro, de Carvalho y otros, y propone nuevas miradas sobre el concepto de Ciudad Educadora, entendiendo a esta última como aquiel lugar en donde no sólo confluye lo político, lo social y lo urbanístico, sino donde los equipamientos desempeñan un papel fundamental.

\section{Palabras clave}

Ciudad Educadora, escuela, equipamientos, deberes, derechos, esperanza.

\section{Abstract}

This paper is based on the concept of Educating City put together by Freire, the Charter of the International Association of Educating Cities, and diverse manifestoes that have been written since its creation at the beginning of the nineties. It relates Educating City concepts from the Human Rights Declaration of 1789 , with those from Freire, Cortina, Genro, de Carvalho, and others and proposes new perspectives for the idea of an Educating City as a place where not only do the political, social and urbanistic merge, but also where equipments play a very important part.

Educating City, school, equipments, obligations, rights, hope. 
lombia), Santa Cruz de la Sierra (Bolivia), Quito (Ecuador), León (México), Montevideo (Uruguay). Es la ciudad, como espacio de cultura, educando a la escuela y todos sus espacios, y la escuela como palco del espectáculo de la vida, educando la ciudad en un intercambio de saberes y de competencias.

En 2004 la ciudad de Sao Paulo se candidatizó para formar parte de la red de ciudades educadoras y presentó el proyecto "Centro Educacional Unificado", CEU, como un ejemplo concreto de construcción de la Ciudad Educadora. El proyecto de los CEU fue concebido como una propuesta intersectorial a la que se sumaron diversas áreas, como medio ambiente, educación, empleo y renta, participación popular, desarrollo local, salud, cultura, deporte y recreación, dentro de la concepción de equipamiento urbano como integrador de la comunidad, con una visión de educación que trasciende el salón de clase y el espacio escolar para extenderse a toda la ciudad. Situados en la periferia de la ciudad de Sao Paulo, los CEU además de ser utilizados por las comunidades como sus espacios de organización y de apoyo en su constitución de sujetos sociales, se concretan en espacios de afirmación de derechos y de promoción de la ciudadanía. Así, los CEU se fundamentan en el concepto de educación con calidad social.

La ciudad dispone de innumerables posibilidades educadoras. La vivencia en la ciudad se constituye en un espacio cultural de aprendizaje permanente por sí solo; "espontáneamente”: “... existe un modo espontáneo, casi como si las ciudades gesticu-

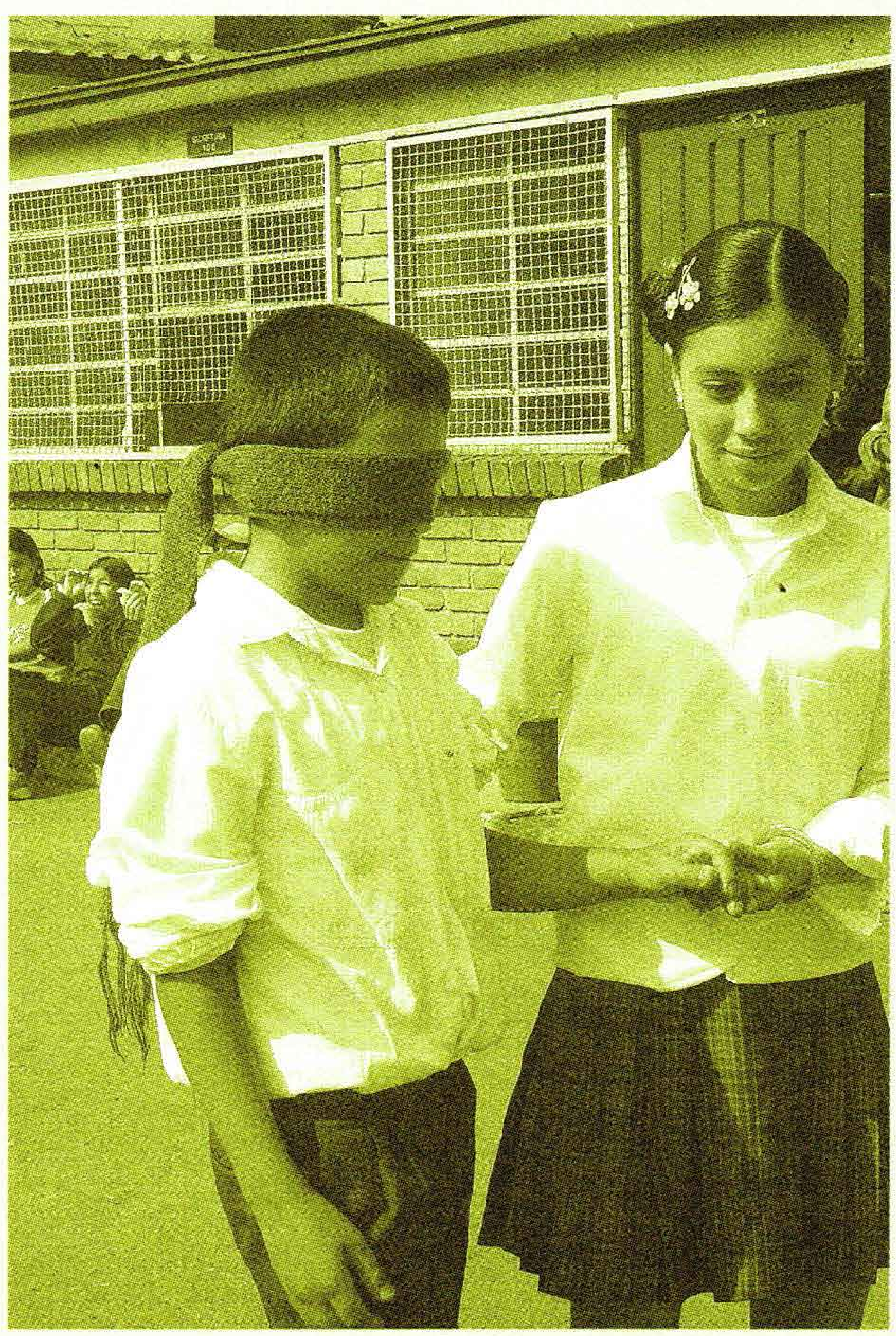

laran, anduvieran, se movieran o hablasen de sí mismas, como si las ciudades proclamaran hechos vividos por mujeres y hombres que pasaron por ellas, pero que quedaron, como una manera espontánea, diría yo, de educar de las ciudades".

Sin embargo, la ciudad puede ser "intencionalmente" educadora.

Una ciudad puede ser considerada como una ciudad que educa, cuando, además de sus funciones tradicionales -económica, social, política y de pres-

2 Paulo Freire, Politica y educación, Sao Paulo, Cortez, 1993, p. 23. 
tación de servicios- ejerce una nueva función cuyo objetivo es la formación para y por la ciudadanía. Para que una ciudad sea considerada educadora requiere promover y desarrollar el protagonismo de todos y de todas -niños, jóvenes, adultos, ancianos- en la búsque-

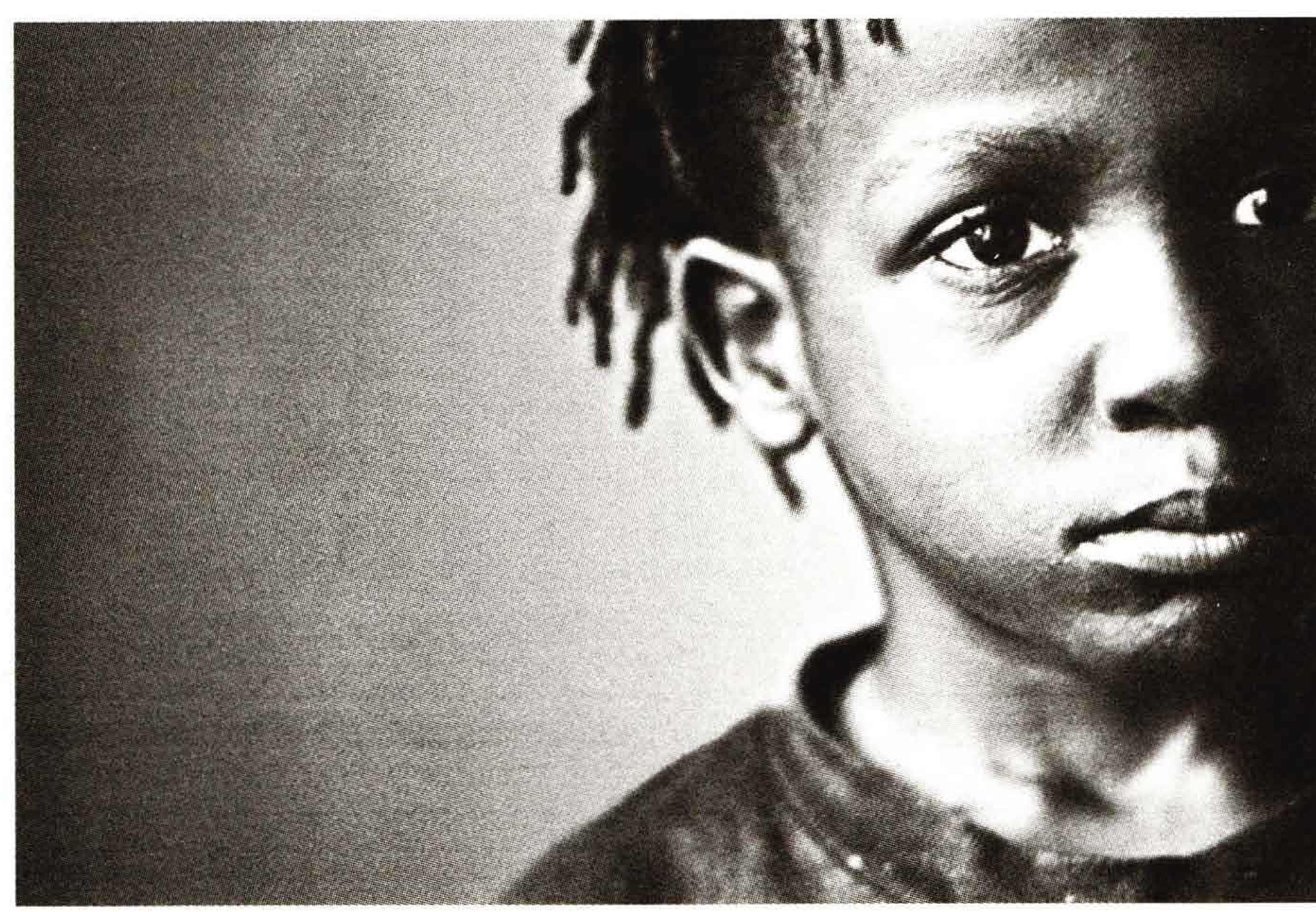
da de un nuevo derecho, el derecho a la Ciudad Educadora: "... en tanto educadora, la ciudad es también educanda. Mucho de su tarea educativa implica nuestra posición política y, obviamente, la manera como ejerzamos el poder en la ciudad y el sueño o la utopía de que impregnemos la política, al servicio de qué y de quién la hacemos".

¿Qué es educar para la ciudadanía? La respuesta a esa pregunta depende de la respuesta a otra pregunta: ¿qué es ciudadanía? Se puede decir que ciudadanía es esencialmente conciencia de derechos y deberes y ejercicio de la democracia: derechos civiles, como seguridad y movilidad; derechos sociales como trabajo, salario justo, salud, educación, vivienda, etcétera; derechos políticos, como libertad de expresión, libertad para votar, libertad de participación

en partidos políticos y sindicatos. No hay ciudadanía sin democracia. Sin embargo, el concepto de ciudadanía es un concepto ambiguo. En 1789 la "Declaración de los Derechos del Hombre y del Ciudadano" establecía las primeras normas para asegurar la libertad individual y la propiedad. Nacía la ciudadanía como una conquista liberal. Hoy el concepto de ciudadanía es más complejo. Con la ampliación de los derechos, nace también una concepción más extensa de ciudadanía. Por una parte, existe una noción consumista de ciudadanía -derecho de la defensa del consumidor- y, por otra, una concepción plena, que se manifiesta en la movilización de la sociedad para la conquista de nuevos derechos y en la participación directa de la población en la gestión de la vida pública; a través, por ejemplo, de la discusión 
Ilo social, moral y cultural, para ser compartidos con otras generaciones. El municipio, en el proceso de toma de decisiones, deberá tener en cuenta el impacto de las mismas. La ciudad ofrecerá a los padres una formación que les permita ayudar a sus hijos a crecer y utilizar la ciudad en un espíritu de respeto mutuo. Todos los habitantes de la ciudad tienen el derecho de reflexionar y de participar en la creación de programas educativos y culturales, y a disponer de los instrumentos necesarios que les permitan descubrir un proyecto educativo, en la estructura y en la gestión de su ciudad, en los valores que fomenta, en la calidad de vida que ofrece, en las fiestas que organiza, en las campañas que prepara, en el interés que manifiesta por ellos y en la forma de escucharlos".

En este contexto, el concepto de "Escuela Ciudadana" gana un nuevo componente: la comunidad educadora reconquista la escuela en un nuevo espacio cultural de la ciudad, integrándola a ese espacio, considerando

En 1993, el Centro de Investigaciones para la Educación y la Cultura, CENPEC, de Sao Paulo, con el apoyo de la UNICEF, escogió quince experiencias significativas de municipios cuyas politicas educativas promovian la democratización de la gestión escolar con participación de la comunidad para fortalecerla como el centro de las decisiones" (CENPEC. La democratización de la enseñanza en 15 municipios brasileros. Sao Paulo, CENPEC/UNICEF, 1993, p.13). Esas experiencias revelaron un nuevo movimiento de innovación en la base de la sociedad, aún al final de la década de los ochenta, precediendo el Movimiento por la Escuela Ciudadana iniciado a comienzos de los años noventa. sus calles y plazas, sus árboles, sus pájaros, sus cines, sus bibliotecas, sus bienes y servicios, sus bares y restaurantes, sus teatros e iglesias, sus empresas y almacenes..., en fin, toda la vida que circula en la ciudad. La escuela deja de ser un lugar abstracto para integrarse definitivamente a la vida de la ciudad y ganar, con eso, nueva vida. La escuela se transforma en un nuevo territorio de construcción de ciudadanía.

La relación entre Escuela Ciudadana y Ciudad Educadora se encuentra en el propio origen etimológico de las palabras "ciudad" y "ciudadano". Ambas derivan de la misma palabra "civis", ciudadano, miembro libre de una ciudad a la que pertenece por origen o adopción, por tanto, sujeto de un lugar; aquel que se apropia de un espacio, de un lugar. Así, ciudad "civitas" es una comunidad política cuyos miembros, los ciudadanos, se auto-

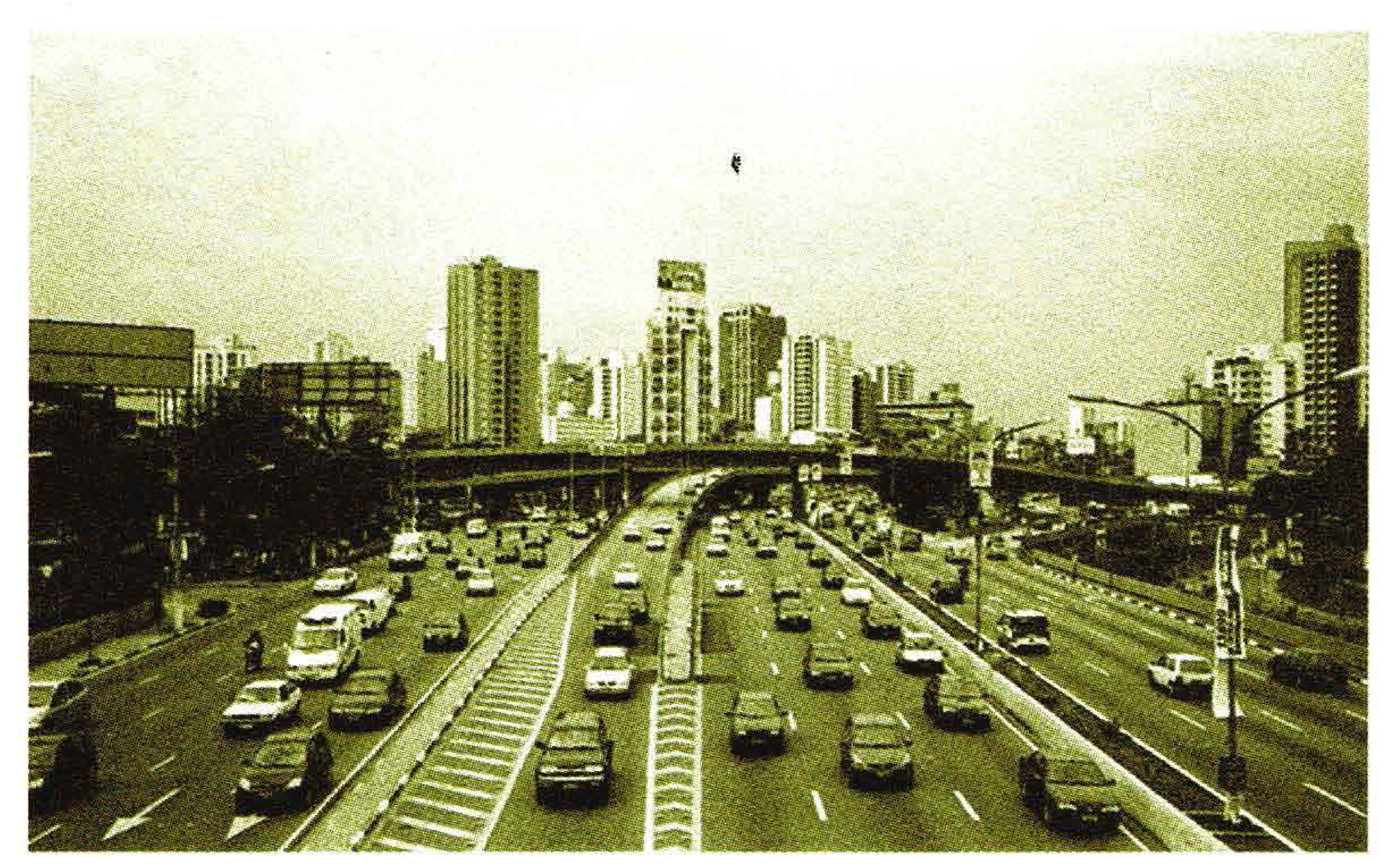




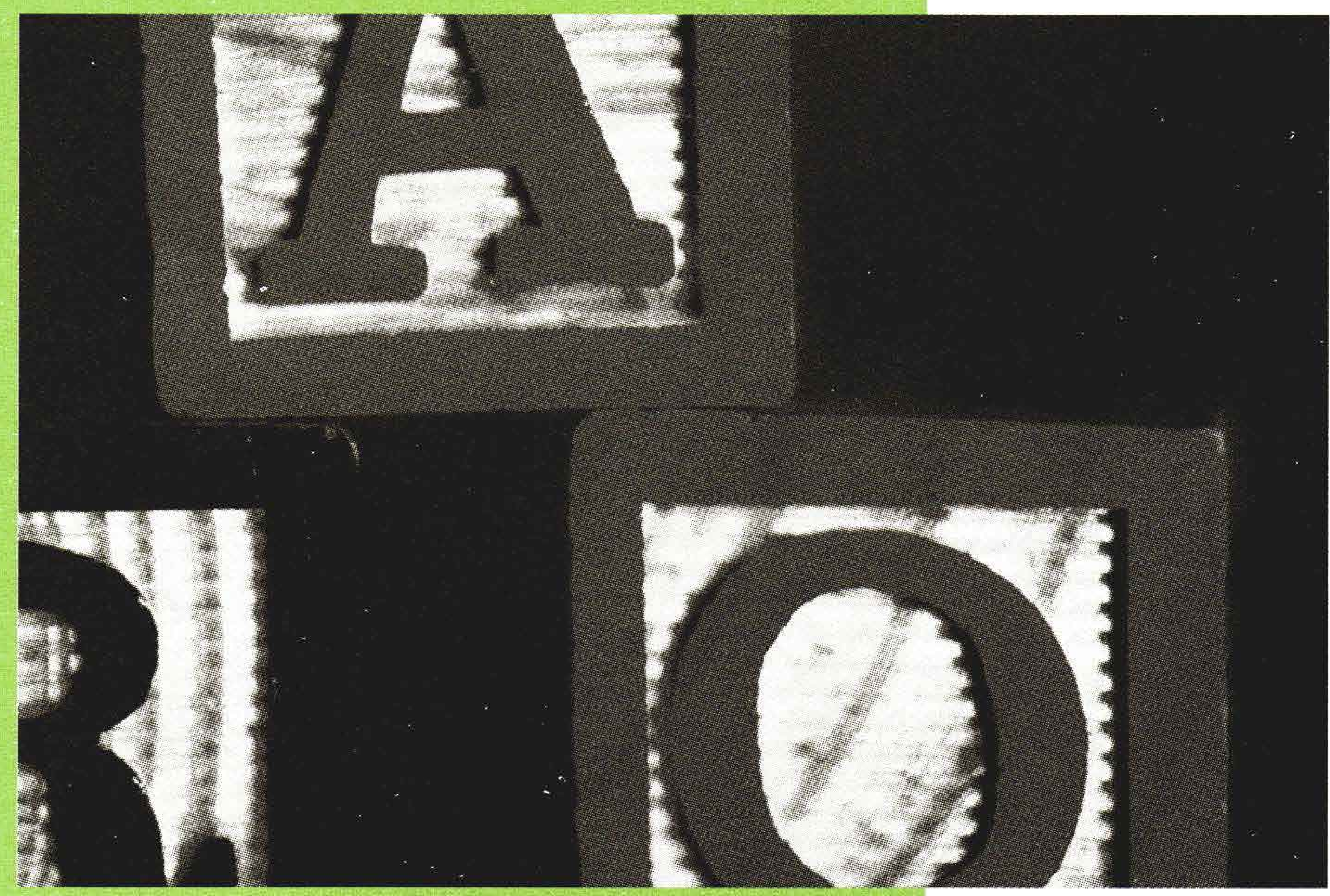

puede hablar de Escuela Ciudadana sin comprenderla como escuela participativa, escuela apropiada por la población como parte de la apropiación de la ciudad a la que pertenece. En este sentido Escuela Ciudadana, en mayor o en menor grado, supone la existencia de una Ciudad Educadora. Esa apropiación se da a través de mecanismos creados por la propia escuela, como el colegiado escolar, la constituyente escolar, plenarias pedagógicas y otros. Ese acto de sujeto de la propia ciudad lleva al interior de la escuela los intereses y necesidades de la población. Ese es el escenario de la ciudad que educa, en el cual las prácticas escolares posibilitan cualificar el entendimiento freireano tanto de la lectura de la palabra escrita como de la lectura del mundo. La ciudad que educa no se queda en lo inmediato, sino que apunta 
a una comprensión más analítica y reflexiva tanto de los problemas cotidianos como de los desafíos del mundo contemporáneo.

El Movimiento de Escuela Ciudadana, centrado inicialmente en la democratización de la gestión y en la planeación participativa, poco a poco amplió sus preocupaciones hacia la construcción de un nuevo currículo -interdisciplinar, transdisciplinar, intercultural-y de nuevas relaciones sociales, humanas e intersubjetivas, enfrentando los graves problemas generados por el aumento de la violencia y el deterioro de la calidad de vida en las ciudades y en el campo.

Una década de innovación y de experimentación con base en una concepción ciudadana de educación y de Ciudad Educadora fue suficiente para generar un gran movimiento, una perspectiva concreta de futuro para la escuela pública, demostrando que la sociedad civil está reaccionando la tendencia oficial neoliberal, a un modelo de internacionalización de la agenda de la educación, que sigue la misma "receta" contenida en "recomendaciones" de organismos internacionales como el Banco Mundial y el FMI.

Tarso Genro , dos veces alcalde de Porto Alegre y hoy ministro de Educación, destaca, entre sus “... 21 tesis para la creación de una política democrá-

6 Tarso Genro, "EL nuevo espacio público: 21 tesis para la creación de una nueva política democrática y socialista". En Cadernos Mais, Folha de $S$. Paulo, 9 de junio de 1996.
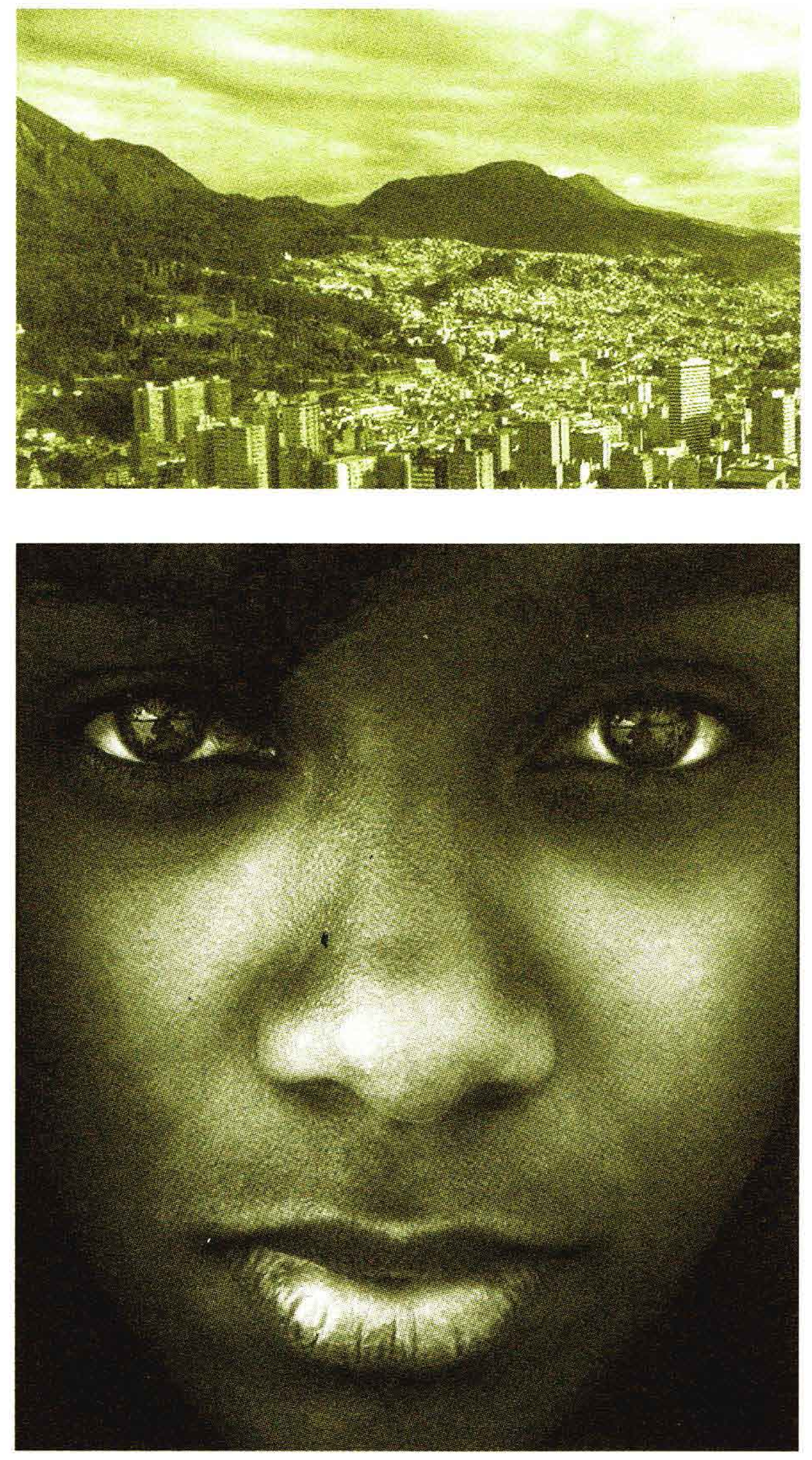


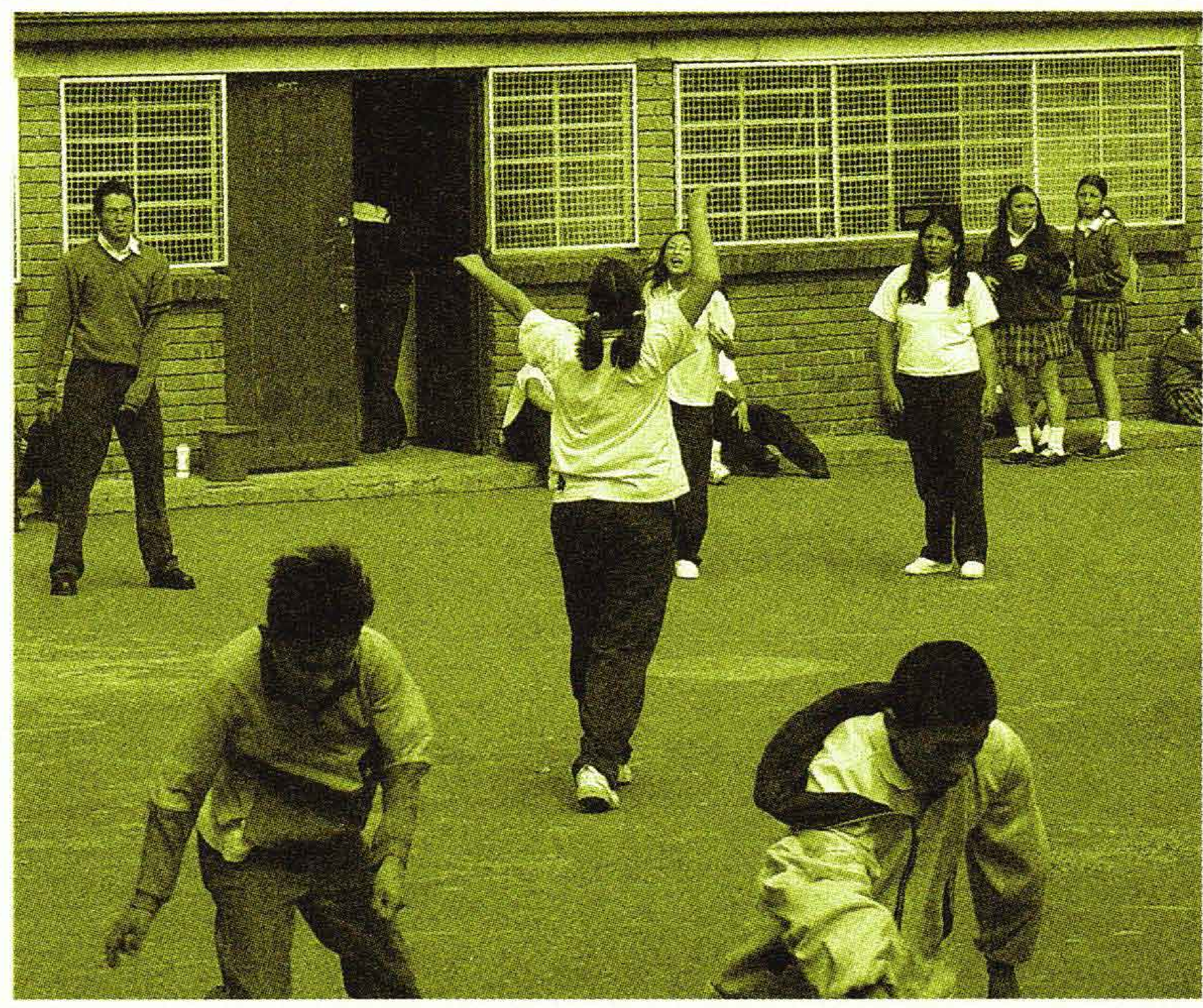

tica y socialista", la necesidad de una "... nueva cultura política, más amplia, de disputa hegemónica y de incorporación de nuevos agentes sociales", y una "... nueva esfera pública con organizaciones locales, regionales, nacionales e internacionales, auto-organizadas", rompiendo la distancia entre Estado y ciudadanía. La Ciudad Educadora es, en verdad, la realización de los objetivos de la propia planeación urbana: la "... promoción y el mejoramiento de las condiciones del hábitat haciendo posible una vida saludable, social, material y espiritual -cultura, educación y trabajo- para todos los habitantes..., mayor eficacia social y mayor eficiencia económica del capital social, es decir, del ambiente construido que es la ciudad, distribuyendo igualitaria o equitativamente los beneficios en la perspectiva de la búsqueda de la sociedad sostenible”.

\section{¿Cuándo y qué podemos hablar de la ciudad que educa?}

Podemos hablar de la ciudad que educa cuando busca instaurar, con todas sus energías, la ciudadanía plena, activa, cuando establece canales permanentes de participación, incentiva la organización de las comunidades para que tomen en sus manos, de forma organizada, el control social de la ciudad. Esta no es una tarea "espontánea" de las ciudades. Necesitamos de voluntad política y de una perspectiva histórica. "La tarea educativa de las ciudades se realiza también a través de su memoria y su memoria no sólo guarda, sino que reproduce, extiende, comunica a las generaciones que llegan. Sus museos, sus centros de cultura, de arte, son el alma del ímpetu creador, de las señales de aventura del espíritu". La ciudad no educa sin la voluntad del ciudadano. "Por eso es importante afirmar que no basta reconocer que la ciudad es educativa, independien-

\footnotetext{
Pompeu Figueiredo de Carvalho, en: Roberto Braga e Pompeu Figueiredo de Carvalho (orgs.), Estatuto de la Ciudad: politica urbana y ciudadanía. Rio Claro, UNESP, 2000, p.42.

8 Paulo Freire, Política y educación, Sao Paulo, Cortez, 1993, p.24.
} 

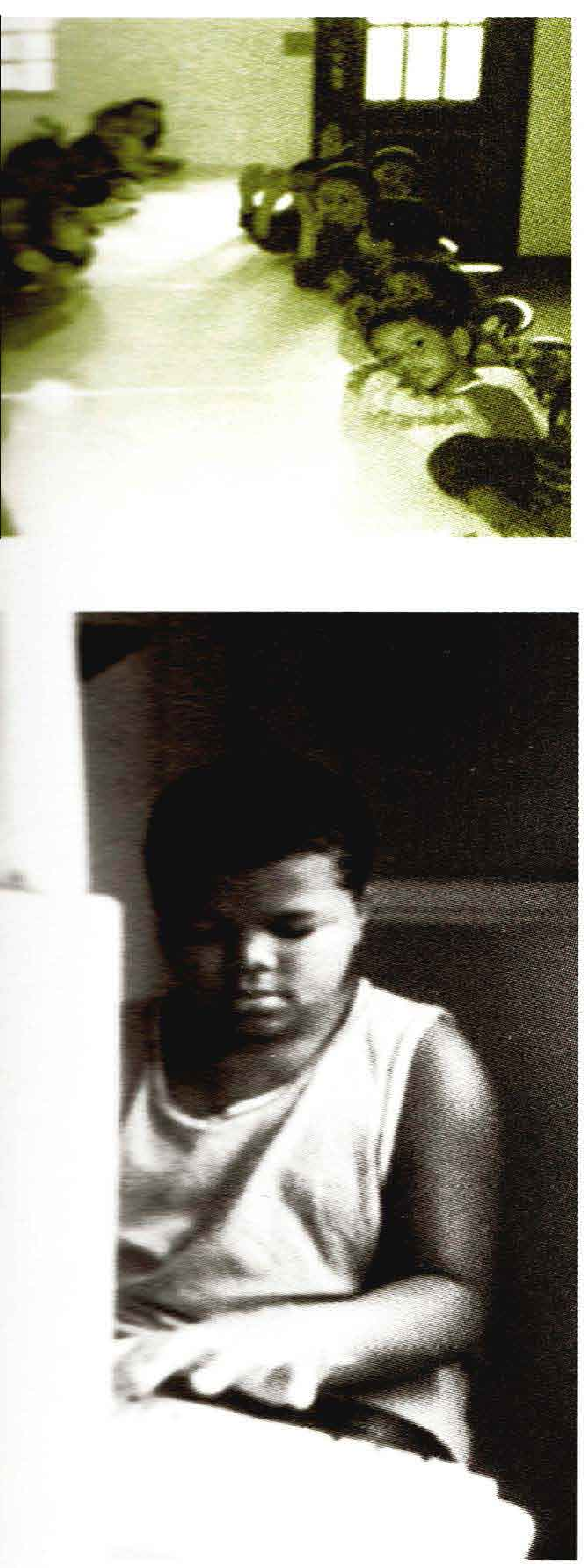

temente de nuestro querer o de nuestro deseo. La ciudad se hace educativa por la necesidad de educar, de aprender, de enseñar, de conocer, de crear, de soñar, de imaginar; que todos nosotros, mujeres y hombres, impregnamos sus campos, sus montañas, sus valles, sus ríos, impregnamos sus casas, sus edificios, dejando en todo el sello de cierto tiempo, el estilo, el gusto de cierta época. La ciudad es cultura, creación; no sólo por lo que hacemos en ella y de ella, sino por lo que creamos en ella y con ella, que también es cultura por la propia mirada estética o de asombro que le damos. La ciudad somos nosotros y nosotros somos la ciudad".

La ciudadanía precisa controlar, en la ciudad, el Estado y el mercado, persiguiendo la utopía de las ciudades justas, producti-

9 Ídm, p. 22. vas, democráticas y sostenibles que son aquellas que consiguen “... romper con el control político de las élites locales y con las formas burocráticas, corruptas y clientelistas de gobernar" , y establecen una nueva esfera pública de decisión no estatal, como el "presupuesto participativo" y la "constituyente escolar", que ya se volvieron emblemáticos en las gestiones populares. Ya salimos del terreno de las propuestas en este campo y van surgiendo nuevas experiencias, en diferentes partes del país, realizadas por diferentes partidos políticos que crean nuevas relaciones, nuevas formas de gestión, nuevos espacios de negociación y estimulan la reapropiación de las ciudades por sus ciudadanos. Y no hay secreto en eso. Basta voluntad política, apoyada en una ética que condene el secreto burocrático y establezca la transparencia, que incorpore el conflicto a prácticas de negociación y que difunda la información.

\section{¿Cuál es el papel de la escuela en la ciudad que educa?}

El papel de la escuela -ciudadana-, en este contexto es contribuir para crear las condiciones que viabilicen la ciudadanía a través de la socialización de la información, de la discusión, de la transparencia, generando una nueva mentalidad, una nueva cultura, en relación con el

10 Silvio Caccia Bava, "La reapropiación de las ciudades". En: Cadernos Le Monde Diplomatique. Porto Alegre, Foro Social Mundial, 2001, p. 18. 

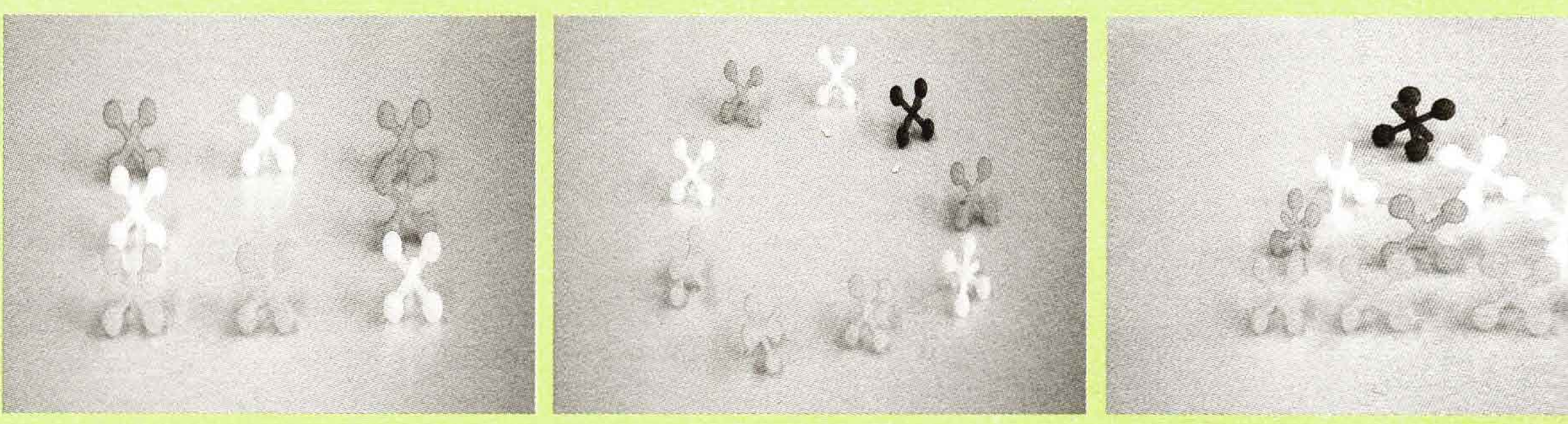

carácter público del espacio de la ciudad. Hay una concepción neoliberal de la ciudad que la considera apenas como un mercado. En este caso, la pedagogía neoliberal tiene por objetivo formar consumidores para el mercado. Hay una concepción emancipadora de la ciudad que viene siendo defendida desde los años setenta. Fue en la Relatoría de Edgar Faure para la UNESCO, en el Año Internacional de la Educación, 1970, y publicada en 1972 con el título Aprender a ser, donde aparece por primera vez la expresión "ciudad educativa" refiriéndose a un proceso de "compenetración intima" entre educación y "vida cívica”. Para esa concepción de educación, el papel de la escuela es formar ciudadanos.

En una perspectiva transformadora, la escuela educa para oír y respetar las diferencias, la diversidad que caracteriza la ciudad y que se constituye en su gran riqueza. El ciudadano de la Ciudad Educadora presta atención al diferente y también al "deficiente", o mejor, al portador de derechos especiales. Para que la escuela sea espacio de vida y no de muerte, requiere estar abierta a la diversidad cultural, étnica y de género y a las diferentes opciones sexuales. Las diferencias exigen una nueva escuela.El gran desafío de la escuela en una ciudad educativa es traducir esos principios en experien- cias prácticas innovadoras, en proyectos para la capacitación ciudadana de la población, para que pueda tomar en sus manos el destino de su ciudad. Ante los nuevos espacios de formación creados por la sociedad de la información, la escuela los integra y articula. Deja de ser "leccionadora" para ser cada vez más "gestora" de la información, constructora y reconstructora de saberes y conocimientos socialmente significativos. Por lo tanto tiene un papel más articulador de la cultura, un papel más orientador e integrador de personas, movimientos, organizaciones e instituciones. En la sociedad de la información el papel social de la escuela se amplía considerablemente. Es una escuela presente en la ciudad y que crea nuevos conocimientos sin dejar de lado el conocimiento históricamente producido por la humanidad, una escuela científica y transformadora.

La ciudad, sobre todo la gran metrópolis, está llegando al límite de lo soportable -violencia, estrés, desempleo, falta de vivienda, de transporte, de saneamiento...-, y no tiene otra alternativa hoy que la de transformarse radicalmente en "nueva ciudad", en Ciudad Educadora. De lo contrario, las ciudades se están encaminando rápidamente a convertirse en espacios de exterminio, sobre todo de los jóvenes. La educación y la 
cultura no lo pueden todo porque existen otros componentes sociales, políticos y, sobre todo, económicos. Pero la ciudad puede contribuir para la construcción de una sociedad saludable, volviéndose amiga y "compañera", como decía Paulo Freire, transformándose en un espacio de formación ético-política de personas que se quieren bien y por eso tienen legitimidad para transformar la vida de la ciudad.

\section{¿Cuál es el papel del profesor en la ciudad que educa?}

La ciudad violenta e insostenible nos introduce en un clima de miedo y desesperanza. Nuestra fuerza como educadores y educadoras es limitada. Nuestras escuelas son también producto de la sociedad. Sin embargo, la esperanza para el profesor, para la profesora, no es algo vacío, de quien deja acontecer. Por el contrario, la esperanza para el profesor encuentra sentido en su propia misión de transformar personas, y a su vez alimentar su esperanza para que consigan construir una realidad diferente, una ciudad nueva, "más humana, menos fea, menos malvada", como acostumbraba decir Paulo Freire. Una educación sin esperanza no es educación.

Educación, en la ciudad que educa, se confunde con el propio proceso de humanización. Respondiendo a la cuestión de, "icómo el profesor puede volverse un intelectual en la sociedad contemporá- q u e e d u c

\section{a:}

\section{a.}

nea?", el gran geógrafo brasilero Milton Santos, fallecido en 2001, respondió: "Cuando consideramos la historia posible y no sólo la historia existente, pasamos a creer que otro mundo es posible. Y no hay intelectual que trabaje sin idea de futuro. Para ser digno del hombre, ya sea del hombre visto como proyecto, el trabajo intelectual y educativo tiene que estar basado en el futuro. Es de esa forma que los profesores pueden volverse intelectuales: mirando al futuro".

\section{Para esto, necesitamos de una pedagogía de la ciudad}

En primer lugar, necesitamos aprender de la ciudad. Paulo Freire decía que el primer libro de lectura es el mundo. Para aprender de la ciudad necesitamos leer el mundo. En general ignoramos la ciudad, reducimós nuestro observar y no la percibimos, y algunas veces hasta la escondemos; damos la espalda para no ver ciertas cosas que suceden en ella. No queremos mirar ciertas cosas de la ciudad para no comprometernos, pues el mirar nos compromete. Miremos nuestro comportamiento en los semáforos cuando somos abordados por los niños y niñas de la calle. Nuestra defensa es no mirarlos a

\footnotetext{
11 Milton Santos, "El profesor como intelectual de la sociedad contemporánea". En: Anales del IX ENDIPE - Encuentro Nacional de Didáctica y Práctica de la Enseñanza, vol. III, Sao Paulo, 1999, p.14.
} 
los ojos. En la ciudad buscamos volver invisibles a muchos seres; hasta en nuestras propias casas cuando mostramos a los visitantes toda la casa y no presentamos la empleada del servicio doméstico que ahi trabaja. Pasamos a través de ellas como si fueran seres transparentes.

Requerimos de una pedagogía de la ciudad para que nos enseñe a mirar, a descubrir la ciudad, para aprender con ella, de ella, para aprender a convivir con ella. La ciudad es el espacio de las diferencias. La diferencia no es una deficiencia. Es una riqueza. Existe una práctica del ocultamiento de las diferencias que procede del miedo de ser tocado por ellas, ya sean diferencias sexuales, diferencias culturales... En general, nuestra pedagogía se dirige a un alumno medio, que es una abstracción. Sin embargo, nuestro alumno real, el alumno concreto, es único. Cada uno de ellos es diferente y necesita ser tratado teniendo en cuenta su individualidad, su subjetividad. Una pedagogía de la ciudad sirve también para que la escuela construya el proyecto político-pedagógico de una "educación en la ciudad 12 ".

En la ciudad que educa el ciudadano camina sin miedo, mirando todos los espacios. Tenemos que aprender a movernos en la ciudad, caminar mucho por nuestras calles. Dejar el carro en casa y caminar. No ver la ciudad apenas a través de fotos y videos. Por eso es importante una educación ciudadana para el tránsito y para la movilización. Precisamos de mapas, de guías. Necesitamos saber dónde nos

\footnotetext{
12 En 1991 , reflexionando sobre sus propuestas para la ciudad de Sao Pau10, Paulo Freire escribió un bello libro con ese título, Educación en la ciudad, Sao Paulo, Cortez, 1991.
}

encontramos. Como sujetos de la ciudad necesitamos sentirnos ciudadanos. La ciudad nos pertenece y porque nos pertenece participamos de su construcción y de su reconstrucción permanentes.

Necesitamos conocer los equipamientos culturales de la ciudad. Es fundamental cualquier programa que intente interconectar los espacios y equipamientos, pues desconocemos nuestra propia ciudad o subutilizamos sus potencialidades. Requerimos empoderar educacionalmente todos sus equipamientos culturales. La ciudad es el espacio de la cultura y de la educación. Existen muchas energías sociales transformadoras que aún están adormecidas por la falta de una mirada educativa de la ciudad. Ese es el objeto de la pedagogía de la ciudad.

Florestan Fernandes acostumbraba repetir que la escuela no educaba para la ciudadanía. Decía que la estructura de poder en América Latina era arcaica y mantenida por la clase dominante, que frenaba la conciencia crítica del pueblo. Esa estructura político-social y económica aún es dominante. Sin embargo, la misma sociedad que crea esa estructura crea también su reacción. Lo que fue socialmente construido puede ser socialmente deconstruido y reconstruido. La contradicción social existe. Por eso encontramos motivos para ser optimistas. Uno de ellos es el surgimiento de movimientos de renovación pedagógica como el de la Escuela Ciudadana y el de la Ciudad Educadora. Estos movimientos no sólo tienen la misma identidad desde el punto de vista etimológico sino que apuntan para el mismo proyecto de futuro, para la construcción de una sociedad educadora-educanda, humanizada, emancipada y solidaria. 